NBER WORKING PAPER SERIES

IS AMERICAN PET HEALTH CARE (ALSO) UNIQUELY INEFFICIENT?

\author{
Liran Einav \\ Amy Finkelstein \\ Atul Gupta \\ Working Paper 22669 \\ http://www.nber.org/papers/w22669 \\ NATIONAL BUREAU OF ECONOMIC RESEARCH \\ 1050 Massachusetts Avenue \\ Cambridge, MA 02138 \\ September 2016
}

We thank Nicolette Zarday for help with the pets claim data. The views expressed herein are those of the authors and do not necessarily reflect the views of the National Bureau of Economic Research.

NBER working papers are circulated for discussion and comment purposes. They have not been peer-reviewed or been subject to the review by the NBER Board of Directors that accompanies official NBER publications.

(C) 2016 by Liran Einav, Amy Finkelstein, and Atul Gupta. All rights reserved. Short sections of text, not to exceed two paragraphs, may be quoted without explicit permission provided that full credit, including $\odot$ notice, is given to the source. 
Is American Pet Health Care (Also) Uniquely Inefficient?

Liran Einav, Amy Finkelstein, and Atul Gupta

NBER Working Paper No. 22669

September 2016

JEL No. H51,I1,I13

\section{ABSTRACT}

We document four similarities between American human healthcare and American pet care: (i) rapid growth in spending as a share of GDP over the last two decades; (ii) strong incomespending gradient;(iii) rapid growth in the employment of healthcare providers; and (iv) similar propensity for high spending at the end of life. We speculate about possible implications of these similar patterns in two sectors that share many common features but differ markedly in institutional features, such as the prevalence of insurance and of public sector involvement.

Liran Einav

Stanford University

Department of Economics

579 Serra Mall

Stanford, CA 94305-6072

and NBER

leinav@stanford.edu

Amy Finkelstein

Department of Economics, E52-442

MIT

77 Massachusetts Avenue

Cambridge, MA 02139

and NBER

afink@mit.edu

\author{
Atul Gupta \\ Stanford University \\ Department of Economics \\ 579 Serra Mall \\ Stanford, CA 94305-6072 \\ atulg@stanford.edu
}




\title{
Is American Pet Health Care (Also) Uniquely Inefficient?
}

\author{
By LiRAn EinAV, AMy Finkelstein, AND ATUl GuPTA*
}

\begin{abstract}
* Einav: Department of Economics, Stanford University, 579 Serra Mall, Stanford, CA 94305-6072 (e-mail: leinav@stanford.edu) and NBER; Finkelstein: Department of Economics, Massachusetts Institute of Technology, 50 Memorial Drive, Cambridge, MA 02142 (e-mail: afink@mit.edu) and NBER; Gupta: Department of Economics, Stanford University, 579 Serra Mall, Stanford, CA 94305-6072 (email: atulg@stanford.edu). We thank Nicolette Zarday for help with the pets claim data.
\end{abstract}

It is well documented that the level and growth of the US healthcare sector is high relative to any other developed country, and that this higher spending is not associated with better health outcomes. Economists and policymakers frequently attribute these facts to idiosyncratic, institutional features of the US healthcare sector, focusing particularly on generous health insurance coverage that insulates consumers from the direct financial consequences of their healthcare consumption decisions, and public sector reimbursement and regulation that provides little incentive for providers to engage in efficient production (e.g. Weisbrod 1991; Fuchs 2014). Such features have been suggested to be the cause of what makes the American healthcare system, in the words of Alan Garber and Jonathan Skinner “uniquely inefficient” (Garber and Skinner 2008).
Naturally, the conventional wisdom is not without its skeptics. An alternative school of thought is that high and rising US healthcare spending is an optimal outcome given individual preferences. For example, Hall and Jones (2007) argue that healthcare is a luxury good (i.e. with an income elasticity above 1) and calibrate a dynamic utility model under which the observed rise in the US health share of GDP is optimal. A related line of argument emphasizes the dramatic technological progress in medicine and the value of life, suggesting that high and rising US healthcare spending may be socially desirable (e.g. Muphy and Topel 2003, Cutler 2004).

These divergent perspectives are intriguing, and difficult to "resolve" with a single convincing answer. Indeed, it may well be that a single answer does not exist, and the unique spending patterns of the US healthcare system result from a combination of factors, some of which reflect specific institutional features of the American system, and some of which reflect “deeper primitives” concerning individual preferences over health and healthcare or the nature of the supply-side of health care. Empirical progress on this 
question is challenging in light of the fact that trying to explain the "uniqueness of the US healthcare system" typically comes down to the comparison of one single data point (the US healthcare system over the last few decades) to similar data points in other countries.

In this paper, we offer a new data point by presenting some simple facts about a different industry: the American pet healthcare industry. We show that many features of the American pet health care sector are, qualitatively, remarkably similar to those of the American human health care sector.

Despite all the obvious caveats when presenting human care spending and pet care spending in the same picture, the two industries share a common feature: the need to make decisions and tradeoffs with respect to medical spending that may potentially improve or extend life. Yet institutionally they are quite different: insurance for pet healthcare is much less common, ${ }^{1}$ and regulation (and public sector involvement more broadly) less prevalent. The similarities we find in the empirical patterns therefore point to deeper primitives that are also influencing demand and supply of health-related products.

\footnotetext{
1 Insurance rate appears to be less than one percent. The North America Pet Health Insurance Association reports that 1.6 million pets were insured in 2015 (https://naphia.org/news/naphia-news/state-
}

In the rest of the paper we document four similarities between American human healthcare spending and American pet healthcare spending: (i) rapid growth in spending as a share of GDP over the last two decades; (ii) a strong income-spending gradient; (iii) rapid growth in the employment of healthcare providers; and (iv) a similar propensity for high spending at the end of life in pets and humans. More details on the data, variable definitions, and analyses are presented in the online appendix.

We view the primary purpose of this short paper as bringing these facts into our collective consciousness to stimulate further discussion and insights. In the concluding section, we offer some initial thoughts of our own.

\section{Patterns of Pet Care Spending Over Time and Across Income Groups}

We use annual data from the Consumer Expenditure Survey (CEX) from 1996-2012 to document patterns of spending on pets, and compare it to three other spending categories: (human) healthcare, housing, and entertainment. (Human) healthcare spending in the CEX represents out of pocket spending by the household on health insurance premiums

industry-report-2016), while the American Pet Products Association reports on a national survey of pets owners, according to which there are more than 160 million dogs and cats owned as pets in 2015-16 (http://www.americanpetproducts.org/press_industrytrends.asp). 
and healthcare. We choose housing and entertainment somewhat arbitrarily, as two other normal goods, that are likely to correlate positively with income, within and across households. The CEX measure of spending on pets is composed primarily of two roughly similarly-sized sub-categories: spending on "pet purchases and medical supplies" and on “veterinary services.” We group these together here, and show in the online appendix that patterns are similar if we restrict to just veterinary services.

We annualize spending, so that our unit of observation is a household-year, and convert spending to 2012 dollars (using the CPI-U price index). We limit our analysis to petowners (who range between 31 percent of households in 1996 to 35 percent in 2012, with a peak of 39 percent in 2010) by conditioning on household-years that report positive spending on pets. All analyses use the CEX sampling weights, which attempt to make it representative of the US population. Our final sample covers 84,341 household-year observations, which cover 57,346 unique households. $^{2}$

\footnotetext{
2 The CEX conducts its interviews every quarter, with spending of participating households typically observed for four-consecutive quarters, which do not necessarily conform to calendar years. We aggregate quarters within a year, and then annualize to the calendar
}

The growth of spending for each category is presented in Figure 1: we normalize each spending category by its 1996 level $^{3}$ and present the growth pattern in each category over our observation period. While housing and entertainment spending have been fairly flat over the 1996-2012 period, healthcare spending has been steadily rising, with spending in 2012 being almost 50\% higher than in 1996. This rapid growth in healthcare spending has, of course been widely documented and commented on previously. The key observation from Figure 1 is that the growth in spending on pets has followed healthcare spending remarkably closely, with 2012 spending being 60\% higher than spending on pets in 1996.

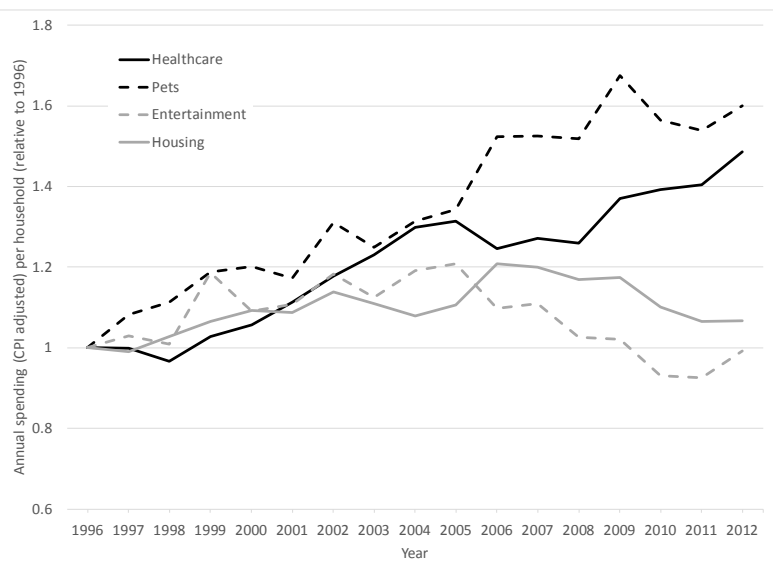

Figure 1. Growth OF Pet CARE Spending

year level. Observations of the same household across calendar years are treated separately.

3 spending levels across categories are naturally very different. Housing spending per household in 1996 is \$25,818 (in 2012 dollars), healthcare is $\$ 5,435$, entertainment is $\$ 7,744$, and pets is $\$ 1,177$. 
Figure plots annual out-of-pocket spending per household in four spending categories. Spending is CPI adjusted and is normalized by the 1996 spending of each spending category. Sample include all households in the CEX with positive spending on pets. See text for more details.

We also explore how spending on each category varies with income. To do so, we use the same sample, and for each category compute the average annual spending by income (using the categorical income brackets available in the CEX). Figure 2 presents the results, normalizing each spending estimate by the average household spending of the lowest income bracket ( $\$ 20,000$ and less) for the corresponding spending category.

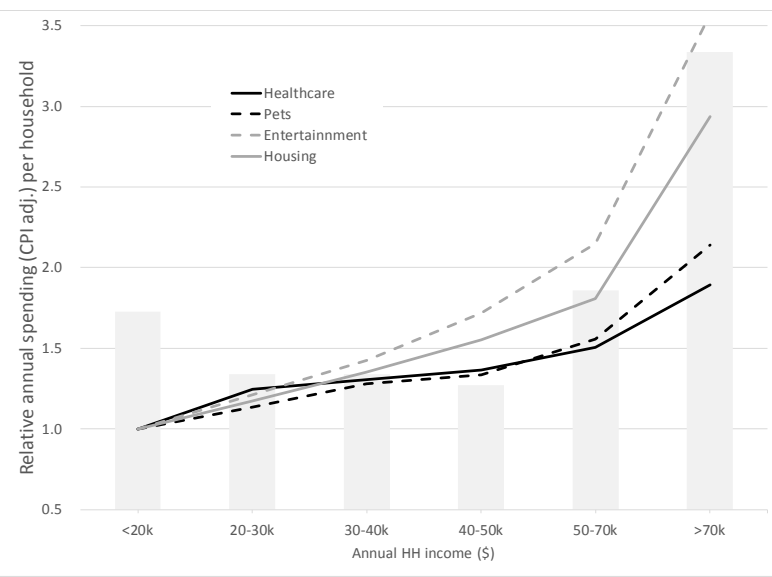

Figure 2. Pet CARE SPENDING By INCOME

Figure plots the relationship between household income and annual spending in four spending categories. Spending is CPI adjusted and is normalized by spending of the lowest income bracket for each spending category. Gray bars report the share of households in the baseline sample in each income category. Sample include all households in the CEX with positive spending on pets except for 8\% with missing income data. See the online appendix for more details.

We make two observations from the results. First, not surprisingly, all spending categories exhibit a fairly strong correlation between income and spending, with households in the highest income category (annual income greater than \$70,000) spending between 114\% (for pets) to $259 \%$ (for entertainment) more than households in the lowest income category. Second, again we find the spending patterns for healthcare by income to be similar to those of pets. This was not obvious a-priori; indeed, we expected that health insurance would flatten this relationship for human healthcare relative to pet health care, where insurance or other redistributional policies are less common.

\section{Growth of The Pet Care Sector}

In this section we use annual data from the County Business Patterns (CBP) from 19962013 to document employment and establishment growth for veterinarians and veterinarian-related services and compare it to employment and establishment growth for physicians and physician-related services.

Figure 3 shows the results. We show employment in each sector and overall relative to its 1996 levels. Somewhat similarly to the growth in spending (Figure 1), we see that the supply of physicians has grown significantly faster than employment growth in other sectors (but, interestingly, slower than the spending growth). Yet, supply of veterinarians grew even faster: while the number of physicians in 2013 was about $40 \%$ higher than that in 1996, 
the number veterinarians almost doubled over the same period. The pattern of establishment growth appear similar.

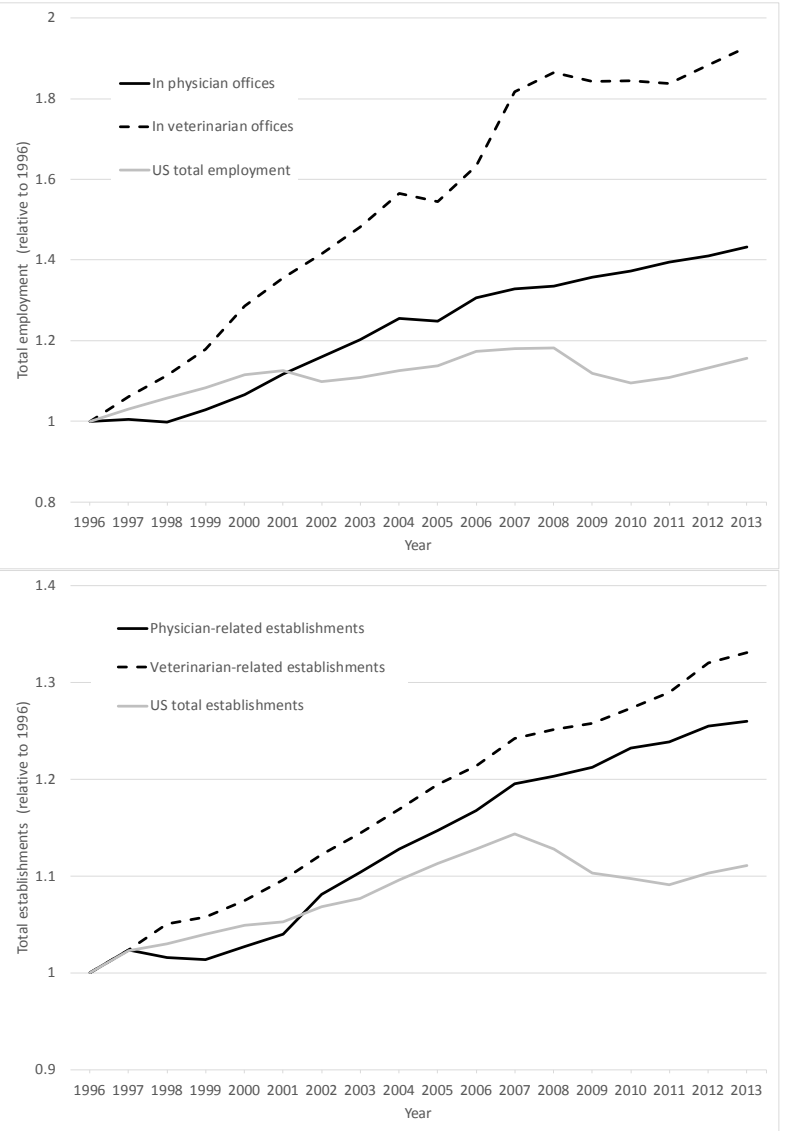

Figure 3. Growth of The Pet Care Sector

Figure plots annual employment (top) and annual number of establishments (bottom) in the two sectors and for the US overall. It is based on data from the US census' County Business Patterns (CBP).

\section{End-of-Life Spending Patterns}

We obtained a small extract of billing data from a single pet hospital in California. The hospital provided us with data on a randomly selected sample of 44 dogs who were treated for lymphoma between 2011 and 2014. We focus on 23 of these dogs who died within our observation period. For those dogs, we obtained detailed information about their claim-by-claim bills, and aggregated total spending as a function of the number of months prior to death.

We then created a similar data extract for Medicare patients. Using data on beneficiaries in Traditional, fee-for-service Medicare, we randomly selected 125 beneficiaries who were diagnosed with lymphoma and died in December of 2008, 2009, 2010, or 2011 (so twelve months of claims data prior to death are observed). Using detailed claim-level information, we construct in parallel total medical spending and used the claims data to aggregate total spending as a function of the number of months before death.

Figure 4 presents the main results. Separately for the small sample of deceased dogs and the larger sample of deceased Medicare beneficiaries, we normalize spending by the average monthly spending in the sample 10 to 12 months before death (which is \$414 for the average dog and \$3,290 for the average Medicare beneficiary), which we define (with all the obvious caveats) as a "regular month."

As one can see, there is a distinct end-of-life spike in spending for both populations. Relative spending in the last month before death is large: 2.18 of a "regular" month for Medicare beneficiaries and 3.48 of a "relative 
month" for dogs. The horizon over which spending spikes is slightly different; for dogs, there is little "excess” spending before the last month (e.g., two months before death spending is only $30 \%$ higher than a regular month), while for Medicare beneficiaries there seems to be an elevated level of spending already 3-4 months prior to death.

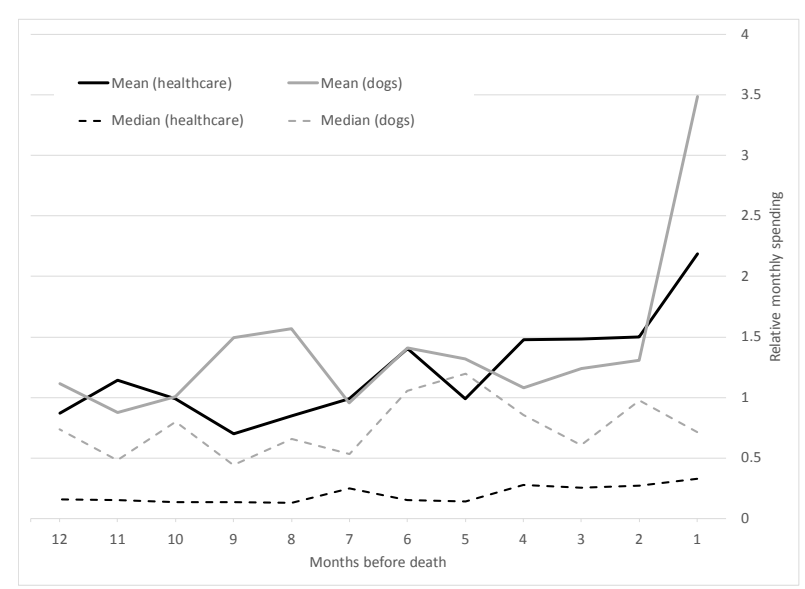

Figure 4. END-OF-Life SPENDING PATTERnS

Figure plots monthly spending for the 12 months prior to death for a small sample of 23 lymphoma-diagnosed dogs and a larger sample of 125 lymphoma-diagnosed Medicare beneficiaries. Monthly spending is normalized by average monthly spending in the 10-12 months prior to death.

Of course, although we find the patterns interesting, it is important to note that unlike the rest of the analysis in this paper - which uses standard, national data sources - the data on end of life spending for dogs with lymphoma relies on an small sample of dogs from one specific pet hospital which likely draws customers who are significantly richer than the average dog owner.

\section{Discussion}

We presented several descriptive patterns about the pet health care industry in the United States, which overall appear to be qualitatively similar to parallel well-documented and discussed patterns of the US (human) health care sector.

All the obvious and appropriate caveats associated with the comparison of human health care and pet care notwithstanding, what drew us to the study of pet health care is the many similarities in the nature of the consumer choice problem, juxtaposed with sharp differences in the institutional environment in which the choice is made. The two industries share many similarities. From demand perspective, treatment decisions are triggered by health episodes that are often difficult to forecast, they are channeled by expert intermediaries who may not fully internalize the financial cost associated with treatment, and they often involve emotional and financial tradeoffs. From supply perspective, the nature of technological progress is similar, and provision is channeled by lengthy education and training and the requirement for occupational licensing. But, in contrast to these similarities between pet healthcare and human healthcare in the nature of the consumer's choice, the institutional environment is very different for pet healthcare. 
Most notably, insurance is much less common in pet care, and regulation, or government involvement more broadly, is not as prevalent. The fact that despite these differences - often mentioned as potential explanations for the large and rapidly growing healthcare sector in the US - some pet health care patterns appear qualitatively quite similar to the analogous human health care pattern, strikes us as noteworthy. It should give us pause before attributing the large and rising healthcare costs in the US solely to the prevalence of insurance and government involvement. ${ }^{4}$. The similar growth patterns in US human and pet healthcare may also suggest that technological change in human healthcare may have spillover effects on related sectors, including perhaps pet healthcare or human care in other countries.

Of course, much more work is needed to explore this further. But at some broad level, these empirical similarities between pet and human health care follow the spirit of Chandra et al. (forthcoming) who suggest that the US healthcare sector may not be as unique as often is claimed, and may benefit from economic insights gleaned from studying other industries. Here, our study of another industry - in this

\footnotetext{
4 The spirit of Tu and May (2007), who find limited shopping behavior by consumers in the context of health-related self-pay markets, is quite similar.
}

case pet health care - suggests the potential importance of further work seeking to understand preferences over health - in addition to the traditional study of insurance, incentives, and institutions - in understanding the US healthcare spending and treatment patterns.

\section{REFERENCES}

Chandra, Amitabh, Amy Finkelstein, Adam Sacarny, and Chad Syverson. 2016 "Healthcare Exceptionalism? Performance and Allocation in the U.S. Healthcare Sector." American Economic Review, forthcoming.

Cutler, David. 2004. Your Money or Your Life: Strong Medicine for America's Health Care System (New York, NY: Oxford University Press, 2004)

Fuchs, Victor R. 2014. "Why Do Other Rich

Nations Spend So Much Less on HealthCare?” The Atlantic, July 23, 2014. Garber, Alan M., and Jonathan Skinner. 2008.

"Is American Health Care Uniquely Inefficient?" Journal of Economic Perspectives 22(4), 27-50.

Hall, Robert, and Charles I. Jones. 2007. “The Value of Life and the Rise in Health 
Spending." Quarterly Journal of Economics 122(1), $39-72$.

Murphy, Kevin M., and Robert Topel. 2003. "The Economic Value of Medical Research." in Measuring the Gains from Medical Research: An Economic Approach, Kevin M. Murphy and Robert Topel, eds. (Chicago: University of Chicago Press).

Tu, Ha T., and Jessica H. May. 2007. "Self-Pay Markets In Health Care: Consumer Nirvana Or Caveat Emptor?” Health Affairs 26(2), w217-w226.

Weisbrod, Burton A. 1991. "The Health Care Quadrilemma: An Essay on Technological Change, Insurance, Quality of Care, and Cost Containment." Journal of Economic Literature XXIX, 523-552. 


\title{
Online Appendix
}

\section{“Is American Pet Health Care (Also) Uniquely Inefficient?”}

\author{
Liran Einav, Amy Finkelstein, and Atul Gupta
}

\section{Consumer Expenditure Survey Data (Figures 1 and 2)}

Figures 1 and 2 use data from the Consumer Expenditure Survey (CEX) from 1996-2012. Prior to 1996 the format of the CEX files differs substantially; 2012 was the latest available year at the time we began this project.

The CEX conducts interviews with households over 5 quarters - the first quarter is a baseline interview, while the remaining 4 quarters record expenditures ("consumption”) each quarter. These four quarters do not necessarily conform to a calendar year. We aggregate quarters within a calendar year. Observations of the same household across calendar years are treated separately. The unit of observation is therefore a household-year. When households do not appear in the survey for all four quarters of a calendar year, we use the available quarters and annualize the total to obtain annual expenditure levels.

We analyze data on four categories of expenditures: pet care, (human) health care, housing, and entertainment. Human health care includes the household's (out of pocket) spending on health insurance premiums, physician, and hospital services. Housing includes spending on mortgages, rent, property taxes, and maintenance costs. Entertainment includes spending on recreational activities and equipment, and television subscriptions and equipment.

Our measure of pet care is based on three expenditure categories: (i) pet purchase and medical supplies; (ii) Veterinary services; and (iii) pet services except Veterinary services. These subcategories account, respectively, for 50, 38, and 12 percent of total pet care spending. Of the two main categories, veterinary services are naturally part of pet health care, while some, but not all of the "pet purchase and medical supplies" category is too. It is unclear what is covered by the smaller "pet services except veterinary services” category. In our main analysis we aggregate all three sub-categories. In Appendix Figures 1 and 2 below we replicate Figures 1 and 2 in the main text limiting spending on pets to just the "Veterinary services" category; the results are qualitatively quite similar (the sample remains the same; a pet owner is still defined as a household with positive spending on pets, regardless of whether the spending is on veterinary services).

We start with the full CEX sample in every quarter, omitting only households (less than one percent) where the head of the household is younger than 18 or older than 90 . This results in a sample of 240,390 household-years. We further limit all analyses to household-years with positive expenditure on pets, which is our proxy for pet ownership. About 35 percent of household-years are included as "pet owners," so that our final sample size is 84,341 householdyears, covering 57,346 unique households. Appendix Table 1 below compares demographics and expenditure on the main categories between our baseline sample and the entire CEX sample. 
When we analyze expenditure by income in Figure 2, we categorize household-years by the household income bucket they report. Household income in the CEX is categorized into $<20,000$, 20,000 - 29,999, 30,000 - 39,999, 40,000 - 49,999, 50,000 - 69,999, >=70,000. The income category is missing for $8 \%$ of the observations.

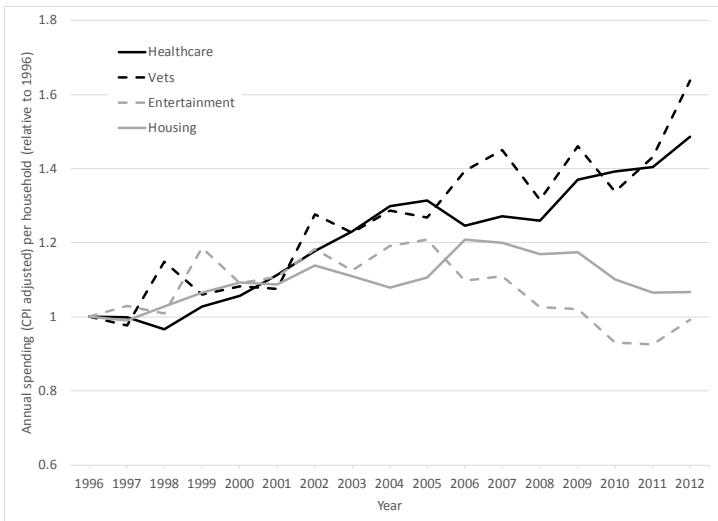

Appendix Figure 1

Expenditure growth (vets)

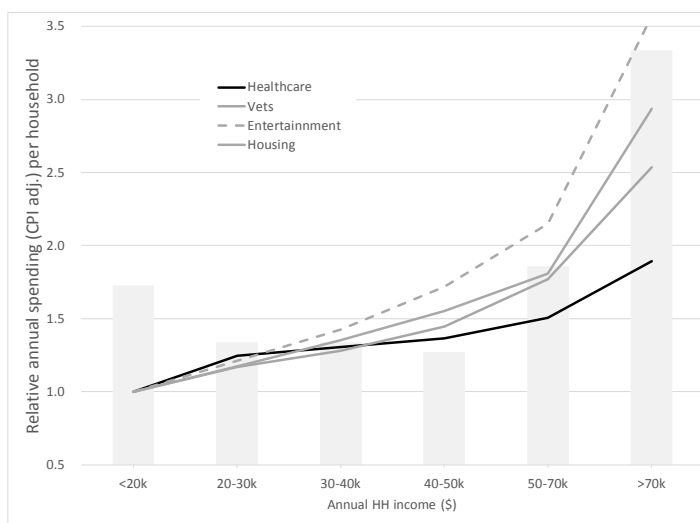

Appendix Figure 2 Spending by income (vets)

\begin{tabular}{lcc}
\hline \hline & HHs w/ positive pet spending & Entire CEX sample \\
\hline HH and head of HH Demographics: & 0.92 & 0.83 \\
White & 0.50 & 0.51 \\
Male & 0.01 & 0.02 \\
Age 18-24 & 0.84 & 0.76 \\
Age 25-64 & 0.15 & 0.21 \\
Age 65-90 & 2.73 & 2.52 \\
Family size & 0.42 & 0.37 \\
College degree & 0.49 & 0.37 \\
HH income >= 50k & & \\
Expenditure categories: & 369 & 130 \\
Pets, medical supplies (2012\$) & 283 & 100 \\
Veterinarian services (2012\$) & 93 & 33 \\
Pet Services (except Vet) (2012\$) & 3,532 & 2,956 \\
Health care (2012\$) & 3,470 & 2,587 \\
Entertainment (2012\$) & 11,626 & 10,185 \\
Housing (2012\$) & 84,341 & 240,390 \\
Observations (HH-year) & & \\
\hline \hline
\end{tabular}

Appendix Table 1

Summary statistics for our baseline sample (1st col) and the entire CEX sample (2nd col) 


\section{US County Business Patterns (Figure 3)}

We use annual data from 1996-2013 from the County Business Patterns (CBP) published by the US Census. We aggregated employment data across standard industry classification codes (the North American Industry Classification System, or NAICS) to the sector level. We analyze total employment as well as employment in two specific sectors: physicians and veterinarians. Physician employment is defined as employment in hospitals, physician offices, dentist offices, and all other health care professional offices. Veterinarian employment is defined as employment at a veterinary office; both veterinary and physician employment measures will therefore include support staff in those offices. We sum employment across counties to arrive at national, annual totals.

The CBP defines an establishment as "a single physical location at which business is conducted or services or industrial operations are performed.” An establishment is not necessarily equivalent to a company or enterprise, which may consist of one or more establishments. A single-unit company owns or operates only one establishment. A multi-unit company owns or operates two or more establishments. The series excludes data on self-employed individuals, employees of private households, railroad employees, agricultural production employees, and most government employees.

\section{End of life care (Figure 4)}

The data on end of life care for dogs come from a large veterinarian hospital in California. Using information on billed drugs, they identified animals who were treated for lymphoma between 2011 and 2014 (the period for which electronic billing data was available). We limit our analysis to dogs, which account for 80 percent of their patients. We received data for a random sample of 300 dogs who had received a biopsy, which is a diagnostic test for lymphoma, among other things. Of these 300 dogs, 44 were identified as having received chemotherapy, and we therefore code them as having lymphoma. Of those 44, we have 23 dogs who died during the period of our data and for whom we observe billing claims for at least 12 months before death. Our analysis of end of life spending pertains to these 23 dead dogs. For those dogs, we obtained detailed information about their claim-by-claim bills, and use this to create a monthly measure of total spending for each of the 12 months prior to death.

The data on end of life care for humans is based on claims data from Traditional Medicare. We selected a random sample of 125 patients who were diagnosed with Lymphoma latest by the penultimate year of life (i.e. if the patient died in 2008, she was diagnosed with Lymphoma by 2007 or earlier), and who died in December of a year between 2008 and 2011. Patients were identified as having Lymphoma based on ICD9 diagnoses codes in the 200xx (Lymphosarcoma and reticulosarcoma) or 202xx (Other malignant neoplasms of lymphoid and histiocytic tissue) families. These two groups are used by the AHRQ Condition Classification System (CCS) to define Lymhoma. For these 125 patients, we measure monthly total Medicare spending in each of the 12 months prior to death. In both cases (dogs and Medicare), we observe claims for the 
last 12 months of life. The spending values span several different years and hence the monthly values are inflation adjusted to be in 2012 dollars using the CPI-U series. 